\title{
Fabrication of High-Performance Flexible Supercapacitor Electrodes with Poly(3,4-ethylenedioxythiophene) (PEDOT) Grown on Carbon-Deposited Polyurethane Sponge
}

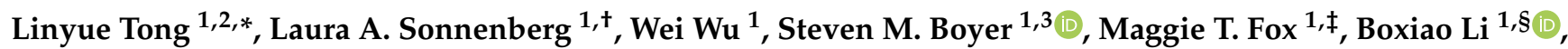 \\ William E. Bernier ${ }^{1}$ (D) and Wayne E. Jones, Jr. ${ }^{1,4, *(D)}$
}

check for updates

Citation: Tong, L.; Sonnenberg, L.A.; Wu, W.; Boyer, S.M.; Fox, M.T.; Li, B.; Bernier, W.E.; Jones, W.E., Jr.

Fabrication of High-Performance Flexible Supercapacitor Electrodes with Poly(3,4-ethylenedioxythiophene) (PEDOT) Grown on Carbon-Deposited Polyurethane Sponge. Energies 2021, 14, 7393. https://doi.org/10.3390/ en14217393

Academic Editor: Francesco Lufrano

Received: 25 September 2021

Accepted: 1 November 2021

Published: 5 November 2021

Publisher's Note: MDPI stays neutral with regard to jurisdictional claims in published maps and institutional affiliations.

Copyright: (c) 2021 by the authors Licensee MDPI, Basel, Switzerland. This article is an open access article distributed under the terms and conditions of the Creative Commons Attribution (CC BY) license (https:// creativecommons.org/licenses/by/ $4.0 /)$.
1 Chemistry Department, Harpur College of Arts and Sciences, Binghamton University State University of New York, 4400 Vestal Parkway East, Binghamton, NY 13902, USA; laura.sonnenberg@temple.edu (L.A.S.); wwu39@binghamton.edu (W.W.); sboyer11@esu.edu (S.M.B.); maggiefox@g.ucla.edu (M.T.F.); libx26@mail.sysu.edu.cn (B.L.); wbernier@binghamton.edu (W.E.B.)

2 Chemistry Department, Culver-Stockton College, One College Hill, Canton, MO 63435, USA

3 Department of Chemistry and Biochemistry, East Stroudsburg University, 200 Prospect St, East Stroudsburg, PA 18301, USA

4 University of New Hampshire, 105 Main Street, Durham, NH 03824, USA

* Correspondence: ltong@culver.edu (L.T.); wayne.jones@unh.edu (W.E.J.J.)

+ Present address: Department of Chemistry, Temple University, 1801 N Broad St, Philadelphia, PA 19122, USA.

$\ddagger$ Present address: Department of Materials Science and Engineering, University of California, 405 Hilgard Avenue, Los Angeles, CA 90095, USA.

$\S$ Present Address: School of Materials Sciences and Engineering, Sun Yat-sen University, 135 XinGangxi Road, Haizhu District, Guangzhou 510275, China.

\begin{abstract}
Composite porous supercapacitor electrodes were prepared by growing poly(3,4-ethylenedioxythiophene) (PEDOT) on graphite nanoplatelet- or graphene nanoplateletdeposited open-cell polyurethane (PU) sponges via a vapor phase polymerization (VPP) method. The resulting composite supercapacitor electrodes exhibited great capacitive performance, with PEDOT acting as both the conductive binder and the active material. The chemical composition was characterized by Raman spectroscopy and the surface morphology was characterized by scanning electron microscopy (SEM). Cyclic voltammetry $(C V)$, charge-discharge $(C D)$ tests and electrochemical impedance spectroscopy were utilized to study the electrical performance of the composite electrodes produced in symmetrically configured supercapacitor cells. The carbon material deposited on PU substrates and the polymerization temperature of PEDOT affected significantly the PEDOT morphology and the electrical properties of the resulting composite sponges. The highest areal specific capacitance $798.2 \mathrm{mF} \mathrm{cm}{ }^{-2}$ was obtained with the composite sponge fabricated by VPP of PEDOT at $110^{\circ} \mathrm{C}$ with graphene nanoplatelet-deposited PU sponge substrate. The capacitance retention of this composite electrode was $101.0 \%$ after 10,000 charging-discharging cycles. The high flexibility, high areal specific capacitance, excellent long-term cycling stability and low cost make these composite sponges promising electrode materials for supercapacitors.
\end{abstract}

Keywords: poly(3,4-ethylenedioxythiophene); carbon material deposited sponge; vapor-phase polymerization; supercapacitor

\section{Introduction}

Research on energy storage is important for the transition to renewable resources, with supercapacitors being of great interest due to the high power density and quick charge/discharge process. As a kind of supercapacitor, electric double layer capacitors (EDLCs) are attractive to researchers for their high efficiency and stability. However, the specific capacitance of the materials based on an electrical double layer mechanism is limited by their specific surface area, since the charge is accumulated electrostatically at the 
interface between electrode and electrolyte [1-4]. Unlike EDLCs, pseudocapacitors achieve their capacitance by fast and reversible redox reactions (faradaic reactions) of the electrode materials during the charge-discharge process $[5,6]$. The capacitance of pseudocapacitors can be 10-100 times greater than that of EDLCs [7], which makes pseudocapacitors more competitive solutions to the energy storage problems.

The most commonly used electrode materials for pseudocapacitors are transition metal oxides and conductive polymers (CPs) [8-11]. Transition metal oxides can provide high specific capacitance, fast and reversible redox reactions, and good stability during cycling. Ruthenium oxides and manganese oxides are examples of this type of pseudocapacitor electrode materials [12-15]. However, the high cost, toxicity and brittle textures of metal oxides limit their development in practical applications. Much effort has been expended on CP-based supercapacitor electrodes due to their high theoretical capacitance, ease of synthesis, and relatively high electrical conductivity compared to transition metal oxides. In addition, the supercapacitors fabricated with CP-based electrodes have enhanced portability and mechanical flexibility at low cost [16-20]. Polyaniline (PANI), polypyrrole (PPy) and polythiophene (PTh) are popular CPs used as electrode materials for pseudocapacitors. In particular, the high stability of poly(3,4-ethylenedioxythiophene) (PEDOT) compared to other CPs makes it a strong candidate as an electrode material in supercapacitors [21]. Although CPs have several advantages over other electrode materials for supercapacitors, they suffer from low mechanical stability and poor rate performance during the chargedischarge process. [22]. The active materials tend to form aggregates, which reduce the accessible sites for redox reactions, resulting in a decrease in specific capacitance [23]. Also, the relatively high electric resistance of pseudocapacitive materials, compared to carbon materials and metals, limits the electron-transfer rate, leading to inferior performance at high charge-discharge current density [24].

To obtain optimal capacitive performance, an effective solution is to fabricate carboncontaining composites with electrochemically active species as electrodes, which can achieve high capacitance via electric double layer mechanism and electrochemical reactions [25-27]. Recently, commercial sponges/foams with macropores have been used as the substrate or the scaffold for the active materials to fabricate supercapacitor electrodes. The macroporosity of the sponge substrate guaranties accessibility to the electrode surface, and the microporosity and mesoporosity of the active materials provide high surface areas [28-30]. A variety of pseudocapacitive materials with this kind of structure have been utilized in supercapacitor electrodes. Ren et al. fabricated graphene foam/polypyrrole composites via a chemical vapor deposition method and a chemical interfacial polymerization method as stretchable supercapacitor electrode materials. The all-solid-state supercapacitor assembled with the resulting composite showed an areal specific capacitance of $258 \mathrm{mF} \mathrm{cm}^{-2}$ [31]. Liang et al. prepared a supercapacitor electrode material by growing $\mathrm{NiCo}_{2} \mathrm{~S}_{4}$ nanosheets on the compressible carbon sponge. The produced electrode achieved a specific capacitance of $1093 \mathrm{~F} \mathrm{~g}^{-1}$ [32]. Moon et al. used a commercial sponge as the substrate to fabricate $\mathrm{ZnCo}_{2} \mathrm{O}_{4}$ / reduced graphene oxide composite through a hydrothermal reaction. A symmetric supercapacitor was assembled with the composite sponge, and a specific capacitance of $1116.6 \mathrm{~F} \mathrm{~g}^{-1}$ was obtained at a scan rate of $2 \mathrm{mV} \mathrm{s}^{-1}$ in aqueous electrolyte [33].

In recent years, one of the research focuses in the supercapacitor field is developing flexible electrode materials. The flexibility of the electrodes allows the design of flexible devices and promotes wearable applications. Various substrates have been used to fabricate flexible composite electrodes for supercapacitors, such as fibers, tapes, and hydrogel and films [34-40]. Both organic and inorganic materials can be the active materials for flexible electrodes, and CPs are among the top choices for this due to their capacitive and mechanical properties. Chen et al. used carbon fiber cloth as the substrate to fabricate a ternary composite electrode. Exfoliated graphene oxide (GO) and molybdenum disulfide $\left(\mathrm{MoS}_{2}\right)$ were physically deposited onto carbon fiber cloth first, and then anchored firmly with the PEDOT polymerization. GO served as the oxidant to initiate PEDOT polymeriza- 
tion and was reduced subsequently. With $1 \mathrm{M} \mathrm{H}_{2} \mathrm{SO}_{4}$ aqueous solution as the electrolyte, the optimized areal specific capacitance was measured as $241.81 \mathrm{mF} / \mathrm{cm}^{2}$ with $C D$ test at a current density of $0.5 \mathrm{~mA} / \mathrm{cm}^{2}$, and the ternary composite exhibited good stability during the charge-discharge process [41]. He et al. electro-synthesized manganese dioxide $\left(\mathrm{MnO}_{2}\right)$ nanospheres on silver plated polyimide film and electrodeposited PEDOT onto those nanospheres. The amount of the two ingredients were governed by electrodeposition time. With vanadium pentoxide $\left(\mathrm{V}_{2} \mathrm{O}_{5}\right)$ as the other electrode and carboxymethyl cellulose sodium (CMC)- $\mathrm{Na}_{2} \mathrm{SO}_{4}$ gel as electrolyte, the flexible $\mathrm{MnO}_{2} @ P E D O T$ composite exhibited an areal specific capacitance of $116.9 \mathrm{mF} / \mathrm{cm}^{2}$ and good cycling stability [42]. Alcaraz-Espinoza et al. deposited carbon nanotubes and polypyrrole onto eggshell membranes to fabricate a flexible composite. The composite was highly porous at nano-scale. With a phosphate-based electrolyte, the highest areal specific capacitance achieved was $564.5 \mathrm{mF} / \mathrm{cm}^{2}$ [43]. Arena et al. prepared a conductive ink by dispersing polypyrrole powder and graphene nanoplatelets with the help of an ionic surfactant, and then applied the ink onto a gold plated flexible plastic film to fabricate a supercapacitor electrode. Nafionlithium hexafluorophospate gel electrolyte was sandwiched by two resulting electrodes to assemble a supercapacitor cell. The areal specific capacitance was about $250 \mathrm{mF} / \mathrm{cm}^{2}$ [44]

In this study, carbon materials (graphite nanoplatelets and graphene nanoplatelets) deposited sponges were fabricated by the "dip and dry" technique with commercially available macro open-cell structured polyurethane (PU) sponge. The graphite nanoplatelet deposited PU sponge (GtPU sponge) and the graphene nanoplatelet deposited PU sponge (GnPU sponge) were employed as the substrates for the polymerization of PEDOT, and the vapor phase polymerization (VPP) method was applied to synthesize PEDOT. Compared to other polymerization methods of PEDOT, the VPP method has produced more crystalline PEDOT with relatively high conductivity $[45,46]$. The simplicity and the substrateadaptability of the VPP method benefitted the electrode preparation and material design significantly $[47,48]$. The resulting PEDOT/GtPU and PEDOT/GnPU composite sponges were applied as the electrodes to assemble symmetric supercapacitors, respectively. The effects of the deposited carbon material (graphite or graphene nanoplatelets) and VPP temperature on the capacitive performance were determined utilizing $C V, C D$ characterization and electrochemical impedance spectroscopy. With the optimized composition and conditions, the resulting composite electrodes in this research exhibited high areal specific capacitance and excellent capacitance retention, and the flexibility of the electrodes allow the fabrication of flexible supercapacitors in the future research. The good capacitive performance, the simplicity of the fabrication process, and the low-cost materials make the resulting composite electrodes a competitive candidate for commercial application.

\section{Materials and Methods}

\subsection{Materials}

Polyurethane (PU) sponge was purchased from 3M Company, Saint Paul, MN, USA. Graphite nanoplatelets (xGnP Grade M, specific surface area of $120-150 \mathrm{~m}^{2} \mathrm{~g}^{-1}$, average particle diameter of $15 \mu \mathrm{m}$ ) and graphene nanoplatelets ( $\mathrm{xGnP}$ Grade $\mathrm{C}$, specific surface area of $750 \mathrm{~m}^{2} \mathrm{~g}^{-1}$, average particle diameter less than $2 \mu \mathrm{m}$ ) were purchased from XG sciences, Inc., Lansing, MI, USA. 3,4-ethylenedioxythiophene (EDOT) and iron (III) $p$ toluenesulfonate hexahydrate $\left(\mathrm{Fe}(\mathrm{PTS})_{3} \cdot 6\left(\mathrm{H}_{2} \mathrm{O}\right)\right)$ were purchased from Sigma-Aldrich, Saint Louis, MO, USA. Pyridine was purchased from Fisher Scientific, Fair Lawn, NJ, USA. Concentrated sulfuric acid $\left(\mathrm{H}_{2} \mathrm{SO}_{4}\right)$ was purchased from J.T. Baker Chemical Company, Center Valley, PA, USA. Ethanol (190 proof) was obtained from Medline Industries, Inc., Lansing, MI, USA. All chemicals were used without further purification. Distilled water was generated by a high-purity water system from Aries Filterworks, Resin Tech, Inc., Camden, NJ, USA. 
2.2. Preparation of Poly(3,4-ethylenedioxythiophene) (PEDOT)/Graphite and PEDOT/Graphene Deposited Polyurethane (PU) Sponge

The typical procedures to fabricate PEDOT/GtPU or PEDOT/GnPU composite sponge are shown in Figure 1. Graphite or graphene nanoplatelets were dispersed in ethanol at $1 \mathrm{mg} \mathrm{mL}^{-1}$ by $1 \mathrm{~h}$ sonication at room temperature. A piece of commercially available PU sponge $(1.5 \mathrm{~cm} \times 1.5 \mathrm{~cm} \times 0.2 \mathrm{~cm})$ was cleaned by adequate application of ethanol, then immersed in the prepared graphite or graphene dispersion overnight (about $10 \mathrm{~h}$ ). Then the GtPU or GnPU sponge was taken out of the dispersion and dried in ambient conditions. The oxidant solution was made by dissolving $\mathrm{Fe}(\mathrm{PTS})_{3} \cdot 6\left(\mathrm{H}_{2} \mathrm{O}\right)$ in ethanol $(0.05 \mathrm{M})$. To minimize acid-initiated polymerization reactions, pyridine was added to the oxidant solution [49]. Oxidant solution was applied to the GtPU or GnPU sponge to saturate it and dried in ambient conditions. The GtPU or GnPU sponge with oxidant was fixed in the center of the space enclosed by two identical Petri dishes, and $100 \mu \mathrm{L}$ of EDOT was added to the bottom one. The whole set was heated in an oven for $1 \mathrm{~h}$ at either 50 or $110^{\circ} \mathrm{C}$. After PEDOT polymerization, the sample was removed from the oven to terminate the reaction. In order to remove the excess $\mathrm{Fe}(\mathrm{PTS})_{3}$ oxidant, pyridine and monomer, the produced composite sponge was rinsed sufficiently with ethanol until no yellow color of oxidant was observed in ethanol. The sample was dried at ambient conditions overnight before chemical and electrical characterizations. The resulting composite sponges maintained mechanical flexibility, even after the color turned dark blue. The representative sample PEDOT/GnPU composite sponge prepared by VPP of PEDOT at $50{ }^{\circ} \mathrm{C}$ exhibited high flexibility as shown in Figure 1c. To address the samples concisely, the composite sponge prepared by VPP of PEDOT at $50{ }^{\circ} \mathrm{C}$ on graphite-deposited PU sponge is denoted as $50 \mathrm{PEDOT} / \mathrm{GtPU}$ and, similarly hereafter, $110 \mathrm{PEDOT} / \mathrm{GtPU}, 50 \mathrm{PEDOT} / \mathrm{GnPU}$ and 110 PEDOT/GnPU composite sponges.
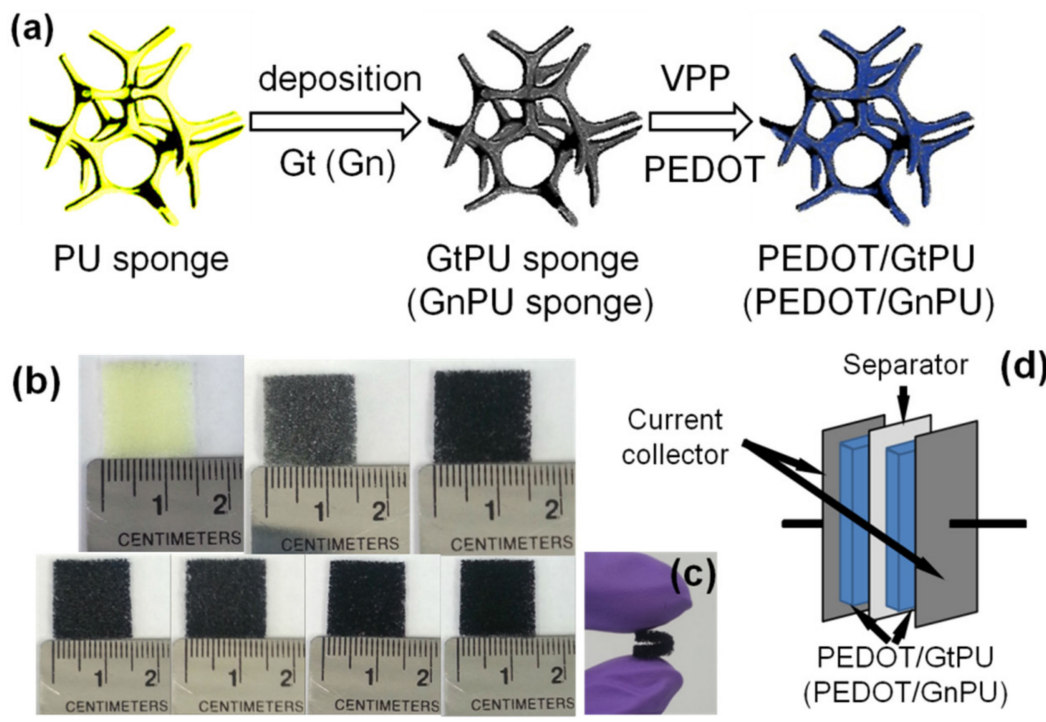

Figure 1. (a) Schematic illustration of the preparation of poly(3,4-ethylenedioxythiophene)/graphite nanoplatelet-deposited polyurethane (PEDOT/GtPU) and PEDOT/GnPU composite sponges. (b) The photographs of PU, GtPU and GnPU sponge (from left to right on the top), 50 PEDOT/GtPU, $110 \mathrm{PEDOT} / \mathrm{GtPU}, 50 \mathrm{PEDOT} / \mathrm{GnPU}$ and $110 \mathrm{PEDOT} / \mathrm{GnPU}$ composite sponge (from left to right at the bottom). (c) A bent strip of 50 PEDOT/GnPU composite sponge. (d) Schematic representation of the supercapacitor cell assembly.

\subsection{Characterization}

The chemical compositions of PU, GtPU, GnPU, PEDOT/GtPU and PEDOT/GnPU sponges were characterized with a DXR xi Raman imaging microscope with the laser wavelength of $532 \mathrm{~nm}$ from Thermo Scientific. The surface morphology was investigated 
with a Zeiss Supra 55 field emission scanning electron microscope (FESEM). The symmetrical supercapacitor cells were assembled with two identical pieces of resulting composite sponge as the two electrodes and a piece of $3 \times 3 \mathrm{~cm}^{2}$ filter paper as the separator. The electrolyte was $1 \mathrm{M} \mathrm{H}_{2} \mathrm{SO}_{4}$ aqueous solution. All the electrical tests were conducted with the two-electrode configuration in ambient conditions on a VMP multichannel potentiostat (Biologic). Capacitance values of the electrode materials were obtained with $C V$ and $C D$ tests. The voltage window for $C V$ was -0.5 to $0.5 \mathrm{~V}$, and 0 to $0.5 \mathrm{~V}$ for $C D$. The capacitance values of the resulting composite sponge electrodes from $C V$ tests were calculated with the formula:

$$
C_{C V}=\frac{1}{v \cdot\left(V_{2}-V_{1}\right)} \int_{V_{1}}^{V_{2}} I d V
$$

where $v$ is the voltage scan rate, $V_{2}-V_{1}$ is the voltage window applied for $C V$ tests, and $I$ is the current response to the voltage change.

The capacitance values from $C D$ tests were calculated with the formula:

$$
C_{C D}=\frac{i \cdot \Delta t}{\Delta V}
$$

where $i$ is the constant discharge current, $\Delta t$ is the discharge time, and $\Delta V$ is the voltage decrease during discharge process, IR drop was excluded. The capacitance of a single electrode was calculated by multiplying the capacitance values from $C V$ or $C D$ tests by 2 since the supercapacitor cells were assembled symmetrically. The areal specific capacitance values were calculated by dividing the capacitance values from $C V$ or $C D$ tests by the area of the sponge $(1.5 \mathrm{~cm} \times 1.5 \mathrm{~cm})$. In the Ragone plot, the areal energy density $E_{\text {areal }}$ is calculated with the formula:

$$
E_{\text {areal }}=\frac{1}{2} \frac{C_{C D} \Delta V^{2}}{3600}
$$

where $C_{C D}$ is the capacitance obtained from $C D$ test, $\Delta V$ is the voltage window of $C D$ test, the calculated energy density is presented in $\mu \mathrm{Wh} \cdot \mathrm{cm}^{-2}$. The areal power density $P_{\text {areal }}$ is calculated with the formula:

$$
P_{\text {areal }}=\frac{3600 E_{\text {areal }}}{\Delta t}
$$

where $\Delta t$ is the discharge time of $C D$ test. The Nyquist plots were obtained from electrochemical impedance spectroscopy to investigate the electrochemical processes.

\section{Results and Discussion}

The composition of the sponge was tracked by Raman spectroscopy during the preparation, shown in Figure 2. In Figure 2a, after graphite nanoplatelets were deposited on PU sponge, the Raman signals of PU sponge [50] were no longer observed. The GtPU sponge sample showed the characteristic Raman signals of graphite, weak D band at $1340 \mathrm{~cm}^{-1}$, $\mathrm{G}$ band at $1560 \mathrm{~cm}^{-1}$ and $\mathrm{G}^{\prime}$ band at $2690 \mathrm{~cm}^{-1}$. The $\mathrm{G}$ band and $\mathrm{G}^{\prime}$ band of graphite were retained in the Raman spectra of 50 PEDOT/GtPU and 110 PEDOT/GtPU, and the $\mathrm{D}$ band was overlapped by the PEDOT signals appearing around the typical range of 1000 to $1600 \mathrm{~cm}^{-1}$ [51]. The most intensive peak of PEDOT at $1430 \mathrm{~cm}^{-1}$ was assigned to $C_{\alpha}=C_{\beta}$ symmetric stretching. All the peaks of PEDOT were contiguous and difficult to be distinguished due to the poor focus on the rough surface of the sponge and low content of PEDOT. Similar results were obtained with the graphene deposited sponges. The GtPU sponge showed the characteristic Raman signals of graphene, intensive D band at $1340 \mathrm{~cm}^{-1}, \mathrm{G}$ band at $1560 \mathrm{~cm}^{-1}$ and $\mathrm{G}^{\prime}$ band at $2670 \mathrm{~cm}^{-1}$. The graphene peaks were still able to be observed in the spectra of 50 PEDOT/GnPU and 110 PEDOT/GnPU, and the signals of PEDOT appeared. The peaks at 1430 and $1510 \mathrm{~cm}^{-1}$ were assigned to $C_{\alpha}=C_{\beta}$ symmetric stretching and $C_{\alpha}=C_{\beta}$ asymmetric stretching from PEDOT structure, respectively. Hence, it is confirmed that the method described above was feasible to prepare PEDOT/GtPU and PEDOT/GnPU composite sponges. 
(a)

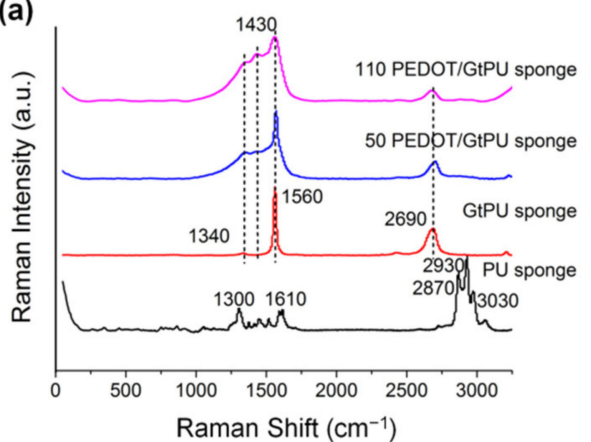

(b)

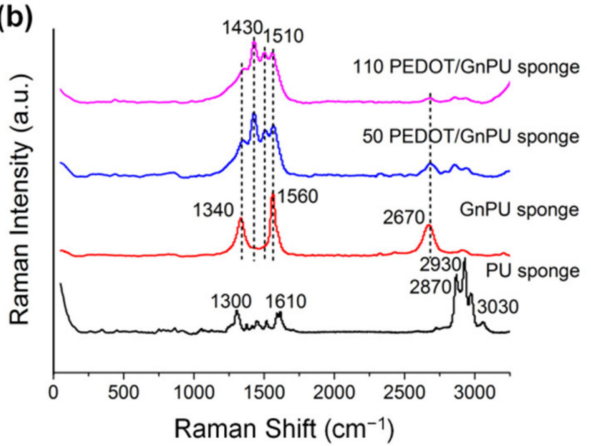

Figure 2. (a) Raman spectra of PU, GtPU, 50 PEDOT/GtPU and 110 PEDOT/GtPU sponge. (b) Raman spectra of PU, GnPU, 50 PEDOT/GnPU and 110 PEDOT/GnPU sponge.

The GtPU sponge and GnPU sponge were prepared with the "dip and dry" method on PU sponge, and the changes in morphology were explored by SEM, shown in Figure 3. The three-dimensional macroporous open-cell structure of bare PU sponge was observed in Figure 3a, and the surface of PU sponge cell was very smooth under high magnification (Figure 3b). After graphite or graphene nanoplatelets deposited onto PU sponge, the three-dimensional structure of the PU sponge scaffold was well maintained (Figure 3c,e), and the surface morphology inside the cells was greatly modified by the deposited graphite or graphene nanoplatelets (Figure $3 d, f$ ). In Figure $3 d$, the surface of PU sponge was completely covered by the lamellar structured graphite nanoplatelets, and in Figure $3 \mathrm{f}$, the fine particle-like graphene nanoplatelets were observed closely packed with no PU smooth surface exposed. The sheet resistance values of these sponges were measured with the four-point probe method. Due to the porosity of the sponge, the measurement of resistance was conducted with four probes (aligned in a line with intervals as $1 \mathrm{~mm}$ ) gently touching the surface of the composite sponge without pressing it. The thickness of the sponge could be considered constant during composite fabrication, therefore, the trend of sheet resistance indicated the trend of resistance. The bare PU sponge was insulating, with the resistance out of range. After graphite or graphene nanoplatelets deposited onto PU sponge, the sheet resistance values decreased to $225 \mathrm{k} \Omega$ /square for GtPU and $707 \mathrm{k} \Omega$ /square for GnPU, respectively. The higher resistance of GnPU than GtPU can be attributed to the discontinuity caused by the smaller flakes of graphene nanoplatelets than graphite nanoplatelets.
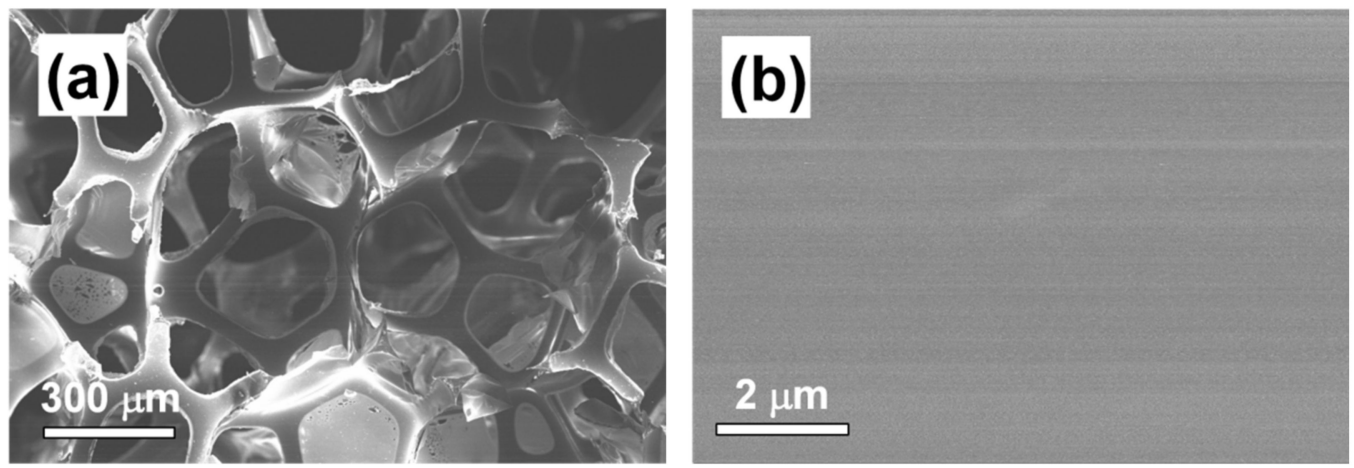

Figure 3. Cont. 

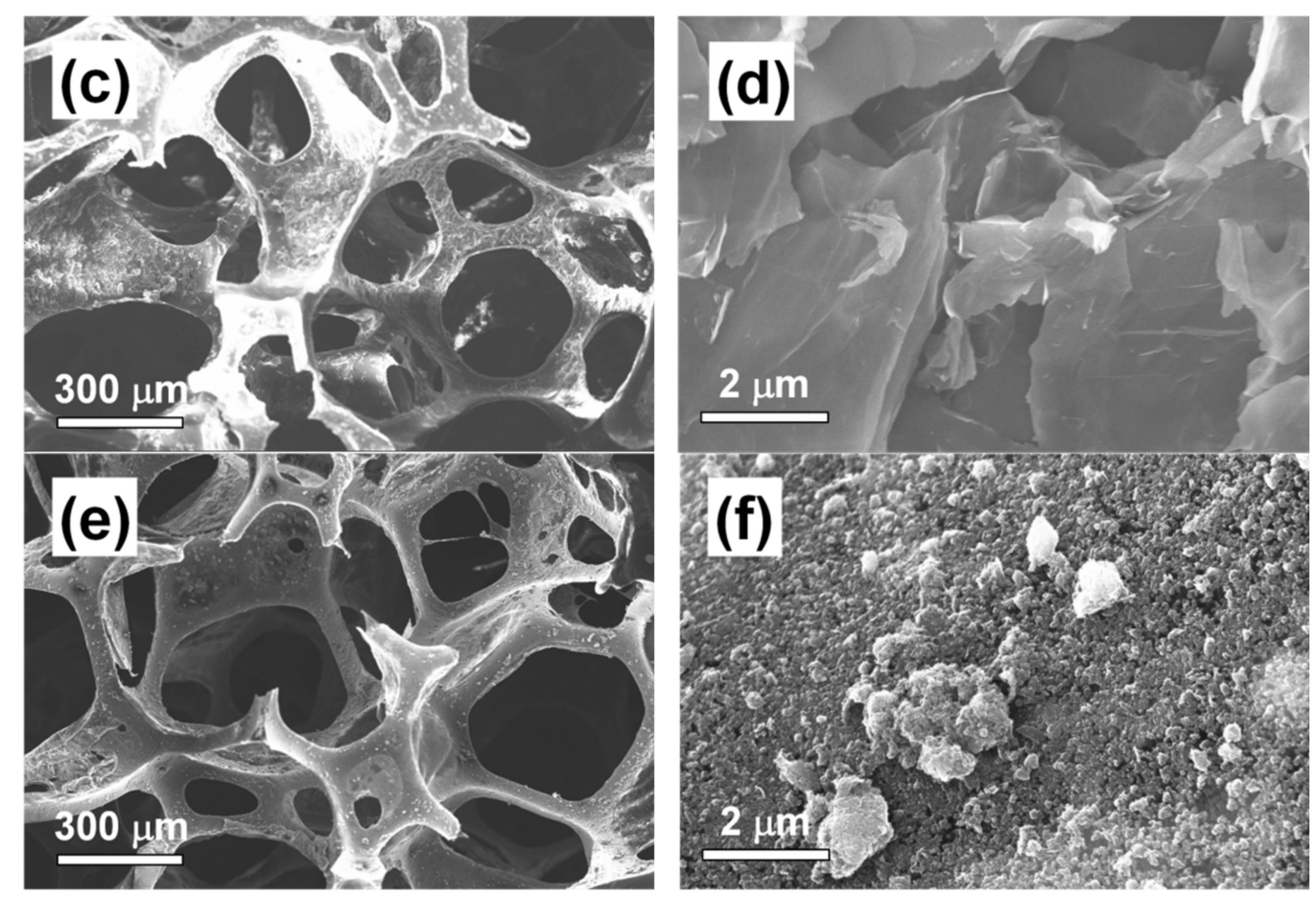

Figure 3. Scanning electron microscopy (SEM) images of PU sponge, GtPU sponge and GnPU sponge under differing levels of magnification. $(\mathbf{a}, \mathbf{b})$ for PU sponge, $(\mathbf{c}, \mathbf{d})$ for GtPU sponge, $(\mathbf{e}, \mathbf{f})$ for GnPU sponge.

The prepared GtPU and the GnPU sponges were used as the substrates for VPP processing of PEDOT. All the composite sponges maintained the macroporous open-cell structure of the bare PU sponge (Figure $4 \mathrm{a}, \mathrm{c}, \mathrm{f}, \mathrm{h}$ ), however, the surface morphology was significantly changed by the growth of PEDOT. In Figure $4 \mathrm{~b}$, the outlines of graphite nanoplatelets were faintly visible on 50 PEDOT/GtPU sponge, most graphite nanoplatelets were attached by the continuous irregularly shaped PEDOT, and no mature porous structure formed by PEDOT. As the polymerization temperature of PEDOT increased to $110^{\circ} \mathrm{C}$, the graphite nanoplatelets were no longer visible due to the higher yield of PEDOT than at $50{ }^{\circ} \mathrm{C}$. Diverse morphologies were obtained on 110 PEDOT/GtPU sponge. Most of the surfaces were covered by PEDOT with many crevices scattered all over (Figure $4 \mathrm{~d}$ ). In some valleys, another kind of morphology was observed. A small amount of PEDOT grew into nano-scale accretive particles (Figure 4e). Other than VPP temperature, different carbon materials deposited on PU sponge also caused the differences in morphology. In 50 PEDOT/GnPU sponge, well-formed submicron-sized porous structures were built by continuous PEDOT, and no graphene nanoplatelets were observed. As the polymerization temperature of PEDOT increased to $110^{\circ} \mathrm{C}$, the coral structure of PEDOT was developed widely with massive nano-scale holes in it. In addition, nano-scale PEDOT particles were also found in 110 PEDOT/GnPU sponge. The sheet resistance values of these composite sponges were also measured with the four-point probe method, and the value for 50 PEDOT/GtPU was $93 \Omega$ /square, $425 \Omega$ /square for 110 PEDOT/GtPU, $273 \Omega$ /square for $50 \mathrm{PEDOT} / \mathrm{GnPU}$, and $817 \Omega$ /square for $110 \mathrm{PEDOT} / \mathrm{GnPU}$. After the polymerization of PEDOT, the resistance values of the composite sponges were decreased significantly compared to their substrates GtPU and GnPU. The decrease in resistance was due to part of the PEDOT polymerized on GtPU and GnPU bridging the carbon flakes as a conductive binder. As the polymerization temperature increased from $50^{\circ} \mathrm{C}$ to $110^{\circ} \mathrm{C}$, the yield of PEDOT was promoted, and more PEDOT was not acting as the conductive binder. In this case, the lower conductivity of PEDOT than graphite and graphene nanoplatelets led to the slight decrease in conductivity of the composite sponges when the polymerization temperature increased from $50{ }^{\circ} \mathrm{C}$ to $110^{\circ} \mathrm{C}$. 

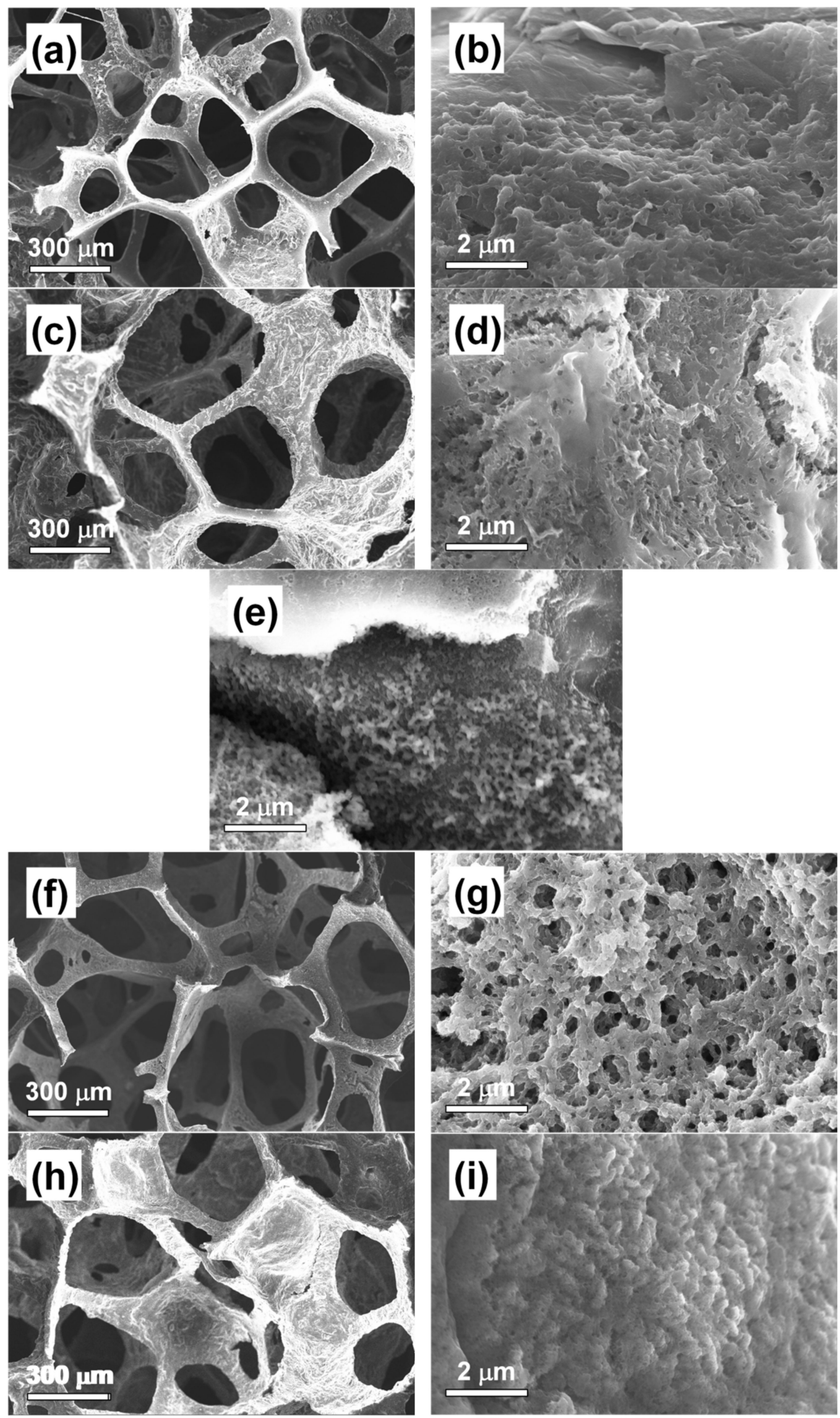

Figure 4. Cont. 


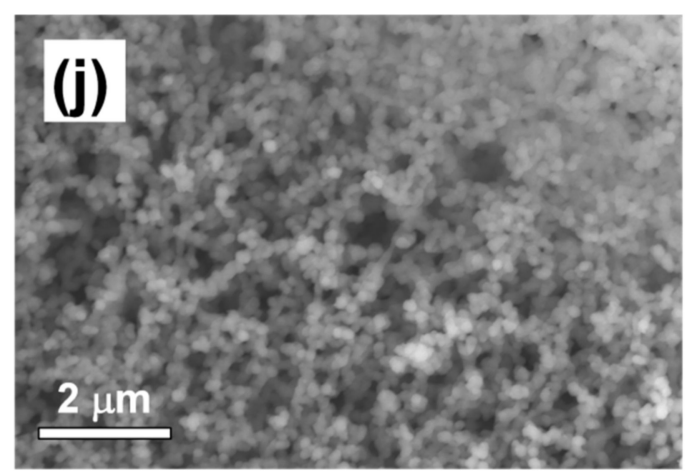

Figure 4. SEM images of 50 PEDOT/GtPU, 110 PEDOT/GtPU, 50 PEDOT/GnPU, 110 PEDOT/GnPU composite sponges under differing levels of magnification. (a,b) for 50 PEDOT/GtPU, (c-e) for 110 PEDOT/GtPU, (f,g) for 50 PEDOT/GnPU, $(\mathbf{h}-\mathbf{j})$ for 110 PEDOT/GnPU.

The variation of morphology of the resulting composite sponges can be attributed to the nucleation of PEDOT. According to the previous work [52], to initiate VPP of PEDOT, EDOT monomer is attacked by the oxidant and forms an EDOT radical. Then PEDOT chains grow as $\mathrm{C}-\mathrm{C}$ bonds are formed between EDOT radicals. The radical termination reactions during PEDOT polymerization result in that PEDOT is more likely to nucleate at the chemically reactive sites. Considering the orbital hybridization of graphite and graphene as an interruption of the honeycomb lattice, the unsaturation of the $\mathrm{p}_{z}$ orbitals and the break of the $\pi$ conjugation on an edge increase the energy of the electrons at the edge sites [53]. Therefore, the edges are more favorable for PEDOT nucleation. As for the graphite and graphene nanoplatelets used in this work, graphene nanoplatelets can provide more edges than graphite nanoplatelets due to their much smaller size of $\mathrm{sp}^{2}$ plane. Hence, the porous structure of PEDOT initiated by nucleation was developed much better on GnPU sponge than on GtPU sponge. When polymerization temperature increased, the concentration of EDOT vapor and the reaction rate were increased, leading to a higher amount of EDOT radical available for polymerization and a higher yield than at lower temperature. These two factors both facilitated the nucleation of PEDOT. In consequence, the porous structure of PEDOT developed better at the relatively higher polymerization temperature.

GtPU, GnPU and the composite sponges prepared with them at different VPP temperatures were employed as electrode materials for supercapacitors, and the assembled cells were studied by cyclic voltammetry $(C V)$ at scan rates from 10 to $100 \mathrm{mV} \mathrm{s}^{-1}$ as shown in Figure 5. The $C V$ curves of GtPU sponge electrodes (Figure 5a) and GnPU sponge electrodes (Figure 5b) both exhibited spindly, or highly distorted rectangular shape, indicating the poor conductivity of the electrodes. Graphite and graphene nanoplatelets are both highly conductive materials, however, the failed connection between scattered nanoplatelets on insulating PU scaffold led to the poor conductivity. After PEDOT was polymerized onto GtPU or GnPU sponge at $50{ }^{\circ} \mathrm{C}$, the resulting composite sponges performed much better in $C V$ curves than their substrates. Fifty PEDOT/GtPU (Figure 5c) and 50 PEDOT/GnPU sponges (Figure 5d) both exhibited a rectangular shape $C V$ curves, suggesting good reversibility for cycling and low internal resistance of the electrode materials. The PEDOT introduced to GtPU or GnPU sponge acted not only as the active material during the electrochemical process, but also the conductive binder for the scattered graphite or graphene nanoplatelets. Hence, both the conductivity and the capacitance of the supercapacitor electrodes were enhanced significantly. In this work, the areal specific capacitance was calculated instead of gravimetric specific capacitance, since the mass of the active electrode material was at milligram/sub milligram level, and excessive error could be introduced during mass measurement. The specific capacitance values of 50 PEDOT/GtPU sponge from a $C V$ test was $78.4 \mathrm{mF} \mathrm{cm}^{-2}$ at $10 \mathrm{mV} \mathrm{s}^{-1}$, and $114.9 \mathrm{mF} \mathrm{cm}^{-2}$ at $10 \mathrm{mV} \mathrm{s}^{-1}$ for 50 PEDOT/GnPU sponge. Based on the morphology observed by SEM, the higher capacitance of 50 PEDOT/GnPU sponge was attributed to the mature submicron-sized porous 
structure. The capacitance values barely decreased at the tested scan rates. Other than the good reversibility of PEDOT during the redox reaction, the low resistance of the porous structure to the ion diffusion also benefited the capacitance retention under high scan rates.
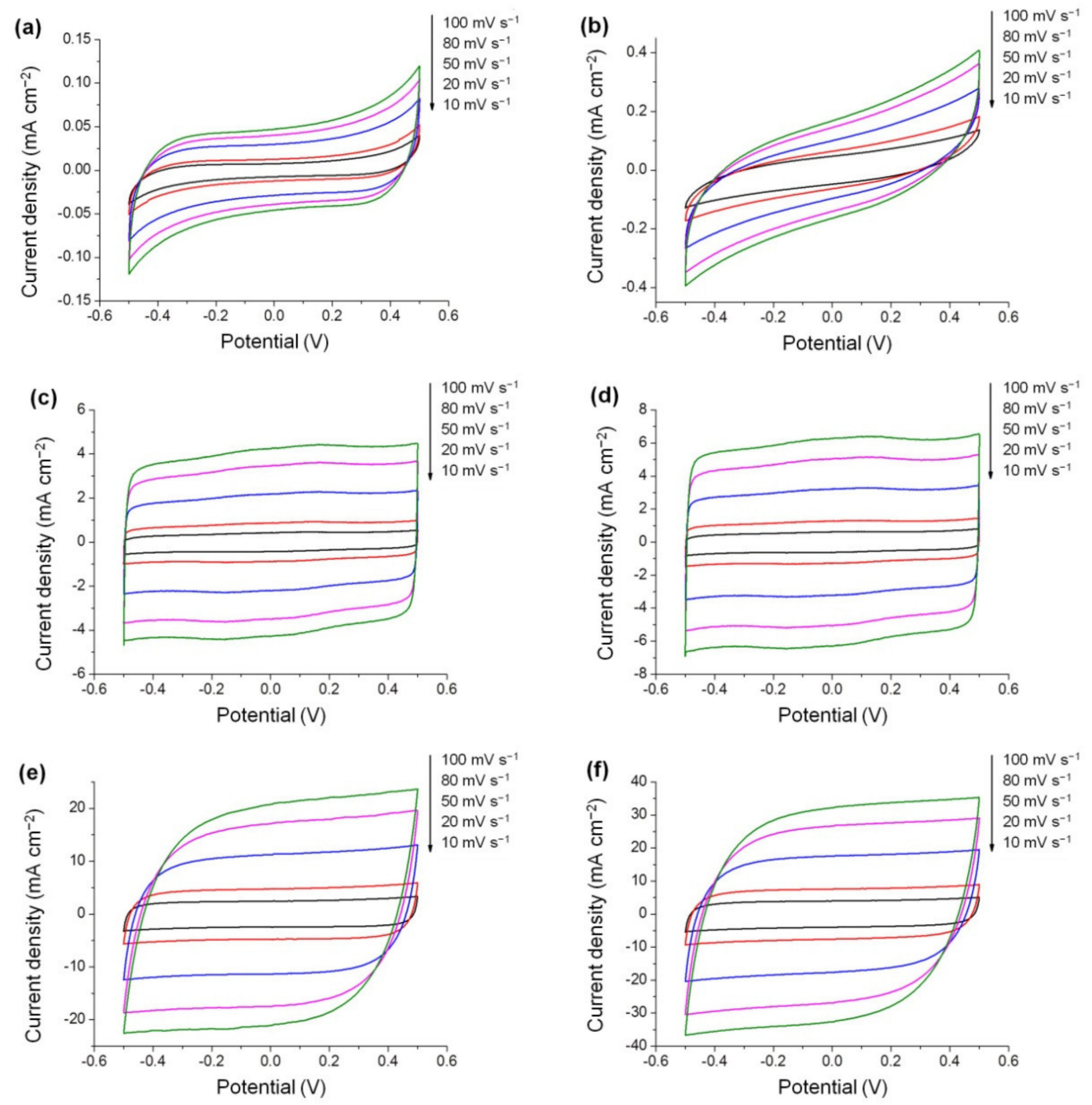

Figure 5. Cyclic voltammetry $(C V)$ curves of symmetric supercapacitor cells assembled with GtPU (a), GnPU (b), 50 PEDOT/GtPU (c), 50 PEDOT/GnPU (d), 110 PEDOT/GtPU (e) and 110 PEDOT/GnPU sponge (f). CV curves were obtained with different scan rates from 10 to $100 \mathrm{mV} \mathrm{s}^{-1}$.

As the polymerization temperature of PEDOT increased to $110^{\circ} \mathrm{C}$, higher yields and more delicate three-dimensional structures of PEDOT were obtained compared to $50{ }^{\circ} \mathrm{C}$ samples. According to the $C V$ curves of 110 PEDOT/GtPU (Figure 5e) and $110 \mathrm{PEDOT} / \mathrm{GnPU}$ electrodes (Figure 5f), the response currents were much higher than those of the composite sponge electrodes prepared at $50{ }^{\circ} \mathrm{C}$, but the response was slightly slower than the $50{ }^{\circ} \mathrm{C}$ samples. The calculated specific capacitance of $110 \mathrm{PEDOT} / \mathrm{GtPU}$ was $477.3 \mathrm{mF} \mathrm{cm}^{-2}$ at $10 \mathrm{mV} \mathrm{s}^{-1}$, and decreased to $342.2 \mathrm{mF} \mathrm{cm}^{-2}$ at $100 \mathrm{mV} \mathrm{s}^{-1}$. For $110 \mathrm{PEDOT} / \mathrm{GnPU}$, the value was $758.8 \mathrm{mF} \mathrm{cm}^{-2}$ at $10 \mathrm{mV} \mathrm{s}^{-1}$, and decreased to $530.8 \mathrm{mF} \mathrm{cm}^{-2}$ at $100 \mathrm{mV} \mathrm{s}^{-1}$. The high capacitance benefited from both the high yield of PEDOT and nano-sized passageway for ion diffusion, which led to the high utilization efficiency of PEDOT during electrochemical process. However, the nano-sized passageway was more resistant to the ion diffusion than the submicrometer-sized channel. Therefore, the current response of the composite sponge electrodes prepared at $110^{\circ} \mathrm{C}$ was slower than the $50{ }^{\circ} \mathrm{C}$ samples. Comparing the morphology of 110 PEDOT/GtPU and 110 PE- 
DOT/GnPU shown in Figure 4, the massive nanometer-sized holes and nano-scale PEDOT particles on 110 PEDOT/GnPU were more effective for the high capacitive performance.

GtPU, GnPU and the composite sponges prepared with them at different VPP temperatures were employed as electrode materials for supercapacitors, and the assembled cells were studied during galvanostatic charge-discharge $(C D)$ test with the current density of $0.1 \mathrm{~mA} \mathrm{~cm}^{-2}$ as shown in Figure 6. The discharge curves of all the samples exhibited the linear relationship between discharge potential and time with a low IR drop, suggesting the low internal resistance of the system and decent conductivity of the electrodes. The specific capacitance values calculated from the $C D$ data are summarized in Table 1 . These results were consistent with the results from $C V$ curves. The VPP process of PEDOT at $50{ }^{\circ} \mathrm{C}$ and $110{ }^{\circ} \mathrm{C}$ both enhanced the capacitance greatly. Under the charge-discharge current of $0.1 \mathrm{~mA} \mathrm{~cm}^{-2}$, the highest capacitance on the substrates of GtPU sponges were obtained with 110 PEDOT/GtPU composite sponge, $494.7 \mathrm{mF} \mathrm{cm}^{-2}$, and on GnPU substrates were 110 PEDOT/GnPU composite sponge, $798.2 \mathrm{mF} \mathrm{cm}^{-2}$. With PEDOT polymerized onto GtPU and GnPU sponge, the capacitances were improved by around two orders of magnitude, and the values increased as the polymerization temperature of PEDOT was set higher.
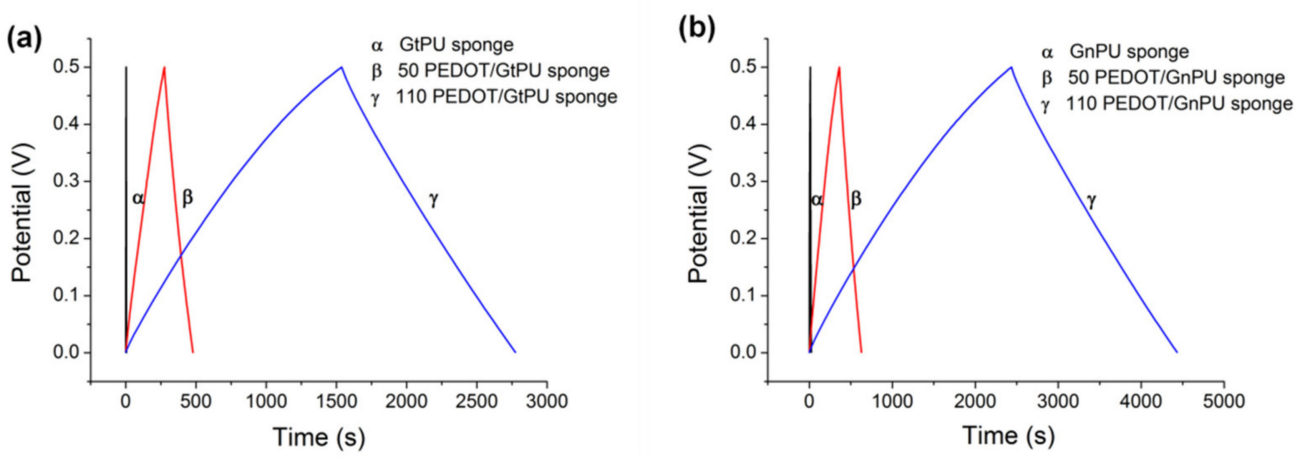

Figure 6. Charge-discharge $(C D)$ testing curves of symmetric supercapacitor cells assembled with GtPU, 50 PEDOT/GtPU and 110 PEDOT/GtPU sponge (a), GnPU, 50 PEDOT/GnPU and $110 \mathrm{PEDOT} / \mathrm{GnPU}$ sponge $(\mathbf{b})$. CD curves were all obtained with the current density of $0.1 \mathrm{~mA} \mathrm{~cm}^{-2}$.

Table 1. Specific capacitance values of GtPU, 50 PEDOT/GtPU, 110 PEDOT/GtPU, GnPU, $50 \mathrm{PEDOT} / \mathrm{GnPU}$ and $110 \mathrm{PEDOT} / \mathrm{GnPU}$ sponge. The calculation was based on $C D$ curves obtained with the current density of $0.1 \mathrm{~mA} \mathrm{~cm}^{-2}$.

\begin{tabular}{cccc}
\hline Substrate & No VPP & 50 VPP PEDOT & 110 VPP PEDOT \\
\hline GtPU sponge & $0.7 \mathrm{mF} \mathrm{cm}^{-2}$ & $81.2 \mathrm{mF} \mathrm{cm}^{-2}$ & $494.7 \mathrm{mF} \mathrm{cm}^{-2}$ \\
GnPU sponge & $4.3 \mathrm{mF} \mathrm{cm}^{-2}$ & $106.6 \mathrm{mF} \mathrm{cm}^{-2}$ & $798.2 \mathrm{mF} \mathrm{cm}^{-2}$ \\
\hline
\end{tabular}

Nyquist plots of the supercapacitor cells assembled with the electrodes of GtPU sponge, GnPU sponge and composite sponges prepared with them via VPP PEDOT at different polymerization temperatures are shown in Figure 7 with the equivalent circuit. In Figure $7 \mathrm{a}$, all three samples showed dramatic increase in capacitive impedance in the low frequency region. The internal resistances (bulk resistance $R_{b}$, charge transfer resistance $R_{c t}$, and one-third ionic resistance $W$ ) were analyzed with the intercept on the real axis from the extrapolation of the approximate linear portion. The approximate linear portion at low frequencies of GtPU was the most deflected from the Z" axis, illustrating the highest internal resistance of GtPU. The linear portion of 50 PEDOT/GtPU was most parallel to the $Z^{\prime \prime}$ axis, indicating low internal resistance, and the excellent capacitive behavior in the low frequency region. The linear portion of 110 PEDOT/GtPU was very close to that of 50 PEDOT/GtPU but slightly more deflected from the Z" axis, indicating the internal resistance of 110 PEDOT/GtPU was slightly higher than 50 PEDOT/GtPU. 
The comparison of internal resistance deduced from Nyquist plots was consistent with the analysis of $C V$ data. At high frequencies, no curve was observed in the Nyquist plot of GtPU sponge, indicating that there was no Faradaic reaction involved and the resistance to ion diffusion and charge transfer was negligible. For 50PEDOT/GtPU, part of a small-radius semi-circle appeared at high frequencies, and the intercept on the $Z^{\prime}$ axis indicated the $R_{\mathrm{ct}}$ was only around $0.6 \Omega \mathrm{cm}^{2}$. The $\mathrm{R}_{\mathrm{ct}}$ is associated with the doping/dedoping process at the electrode/electrolyte interface. Therefore, the fact that the redox reactions on 50 PEDOT/GtPU responded fast and the ion diffusion resistance was low is convincing. For 110 PEDOT/GtPU, the radius was larger and the intercept on the $Z^{\prime}$ axis was around $1.1 \mathrm{ohm}$, indicating the current response was slower and ion diffusion resistance was higher than 50PEDOT/GtPU. In Figure 7b, similar results were obtained with GnPU, 50 PEDOT/GnPU and 110 PEDOT/GnPU sponges. The internal resistance of $50 \mathrm{PEDOT} / \mathrm{GnPU}$ was the lowest, and GnPU was the highest. Different from GtPU sponge, there was a curve portion observed at high frequencies with GnPU, due to the higher ion diffusion resistance than GtPU sponge. The comparison between 50 PEDOT/GnPU and $110 \mathrm{PEDOT} / \mathrm{GnPU}$ was similar to that between $50 \mathrm{PEDOT} / \mathrm{GtPU}$ and $110 \mathrm{PEDOT} / \mathrm{GtPU}$, and $50 \mathrm{PEDOT} / \mathrm{GnPU}$ underwent a faster doping/de-doping process and had lower ion diffusion resistance than 110 PEDOT/GnPU. All the conclusions drawn from Nyquist plots were consistent with the analysis based on SEM, CV and CD measurements.
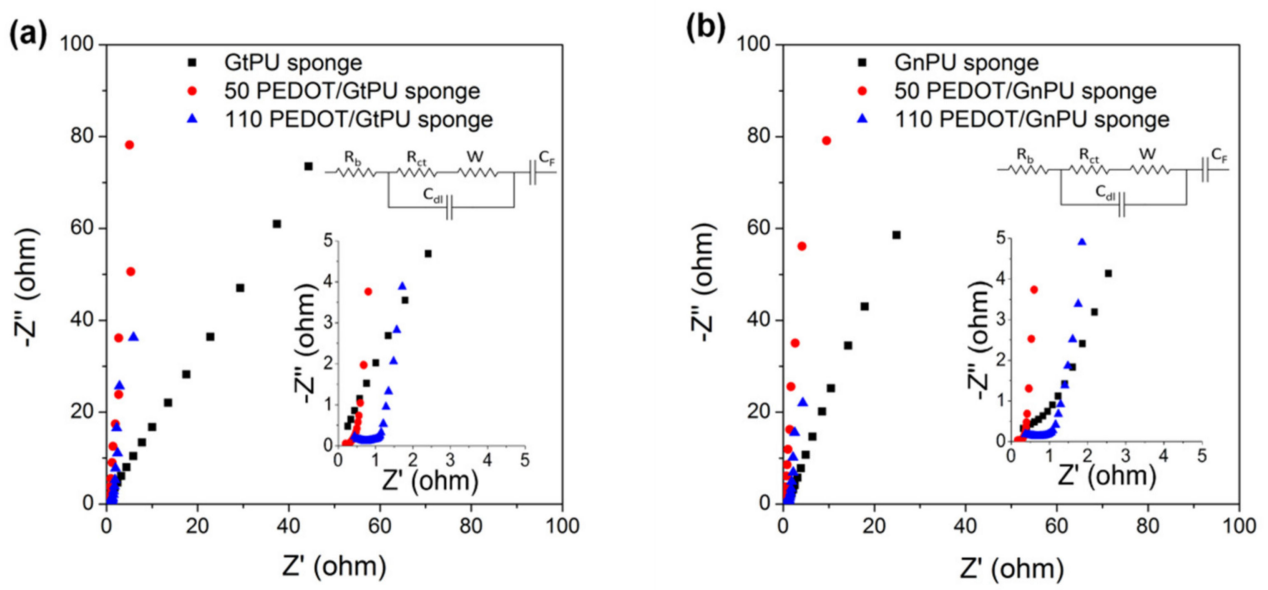

Figure 7. Nyquist plots for the symmetric supercapacitor cells assembled with GtPU, 50 PEDOT/GtPU and 110 PEDOT/GtPU sponge (a), GnPU, 50 PEDOT/GnPU and 110 PEDOT/GnPU sponge (b). Nyquist plots were all obtained with $10 \mathrm{mV}$. The high frequency regions are showed as the inset.

According to the results and analysis above, given the PEDOT polymerization parameters, the composite sponges prepared with GnPU sponge substrates performed better than those prepared with GtPU sponge substrates. Due to the edge energy state, graphene nanoplatelets were more favorable for PEDOT nucleation and porous structure development than graphite nanoplatelets. More electrochemical tests were conducted to further investigate the rapid current response of $50 \mathrm{PEDOT} / \mathrm{GnPU}$ and the high specific capacitance of 110 PEDOT/GnPU.

We further studied $50 \mathrm{PEDOT} / \mathrm{GnPU}$ and $110 \mathrm{PEDOT} / \mathrm{GnPU}$ with $C D$ tests from 0 to $0.5 \mathrm{~V}$ with current density from low $0.1 \mathrm{~mA} \mathrm{~cm}^{-2}$ to high $20 \mathrm{~mA} \mathrm{~cm}^{-2}$. The calculated specific capacitance values under varied current densities are shown in Figure 8a,b. After a small capacitance increase from $0.1 \mathrm{~mA} \mathrm{~cm}{ }^{-2}$ to $0.4 \mathrm{~cm}^{-2}$, the specific capacitance of $50 \mathrm{PEDOT} / \mathrm{GnPU}$ decreased slowly as the current density increased (Figure 8a). The capacitance increase was attributed to the self-activation of PEDOT, and the redox reactions on a small portion of PEDOT could not keep up with the applied current when current density increased. The specific capacitance obtained at $20 \mathrm{~mA} \mathrm{~cm}^{-2}$ was $101.2 \mathrm{mF} \mathrm{cm}^{-2}$, it was $94.9 \%$ of the initial value $106.6 \mathrm{mF} \mathrm{cm}^{-2}$ at $0.1 \mathrm{~mA} \mathrm{~cm}^{-2}$ and $84.7 \%$ of the highest 
value $119.5 \mathrm{mF} \mathrm{cm}^{-2}$ at $0.4 \mathrm{~mA} \mathrm{~cm}{ }^{-2}$. The high capacitance retention at high current density confirmed the fast doping/de-doping process and low ion diffusion resistance of 50 PEDOT/GnPU. In Figure 8b, the specific capacitance of 110 PEDOT/GnPU decreased significantly as the testing current density increased. There was no increase observed at the first several tested current densities since the decrease caused by increasing applied current was dominating the performance. The capacitance value $304.8 \mathrm{mF} \mathrm{cm}^{-2}$ obtained at $20 \mathrm{~mA} \mathrm{~cm}^{-2}$ was $38.2 \%$ of the initial value 798.2 at $0.1 \mathrm{~mA} \mathrm{~cm}^{-2}$. The higher yield of PEDOT and nano-scale porous structure on 110 PEDOT/GnPU caused the lower conductivity and higher ion diffusion resistance than 50 PEDOT/GnPU. It was more difficult for 110 PEDOT/GnPU to keep up with the applied current, and more PEDOT in $110 \mathrm{PE}-$ DOT/GnPU could not respond to the applied current quickly compared 50 PEDOT/GnPU. Although the specific capacitance of 110 PEDOT/GnPU decreased significantly as the current density increased, the capacitance value of $110 \mathrm{PEDOT} / \mathrm{GnPU}$ was still higher than $50 \mathrm{PEDOT} / \mathrm{GnPU}$ at the highest tested current density of $20 \mathrm{~mA} \mathrm{~cm}^{-2}$.

(a)
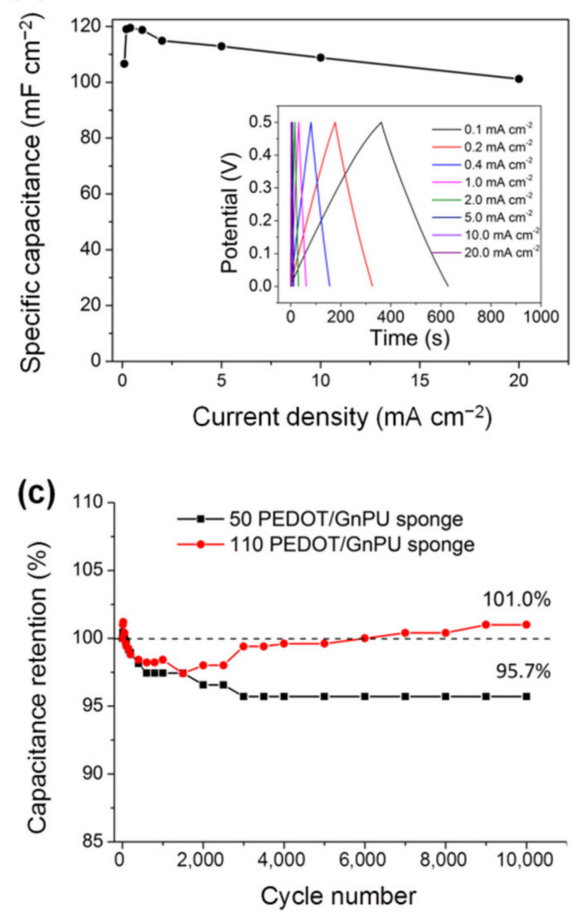

(b)

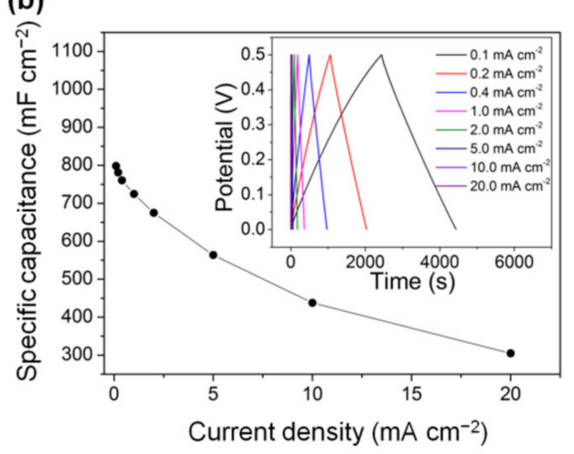

(d)

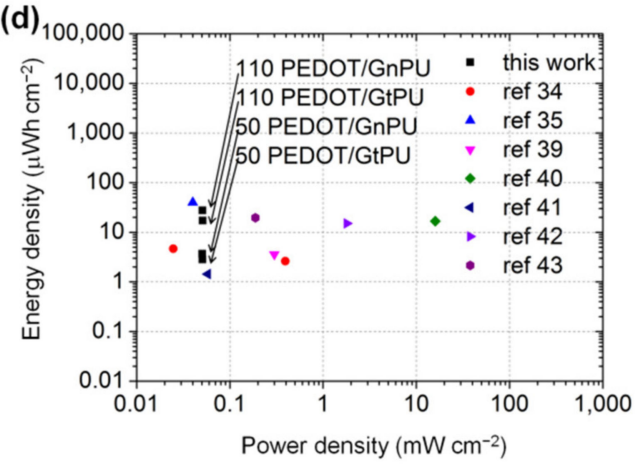

Figure 8. Specific capacitance values of the symmetric supercapacitor cells assembled with 50 PEDOT/GnPU sponge (a) and 110 PEDOT/GnPU sponge (b) measured with different scan rates from 0.1 to $20 \mathrm{~mA} \mathrm{~cm}^{-2}$. The insets show the $C D$ curves under each scan rate. (c) Specific capacitance retention versus cycle number for the symmetric supercapacitor cells assembled with 50 PEDOT/GnPU or $110 \mathrm{PEDOT} / \mathrm{GnPU}$ composite sponge. The $C D$ tests were measured with the scan rate of $20 \mathrm{~mA} \mathrm{~cm}^{-2}$. (d) Areal-normalized Ragone plot showing the comparison with cited works.

The long-term cycling stability of 50 PEDOT/GnPU and 110 PEDOT/GnPU composite sponges was investigated by $C D$ tests from 0 to $0.5 \mathrm{~V}$ with current density of $20 \mathrm{~mA} \mathrm{~cm}^{-2}$ for 10,000 cycles, shown in Figure 8c. The specific capacitance of 50 PEDOT/GnPU sponge slightly increased in the first 50 cycles due to the self-activation of PEDOT, and then slowly decreased till the end of the test. The decrease in capacitance is mainly caused by polymer structural degradation from the continuous expansion and contraction of the polymer during the repeated charging and discharging processes [54,55]. The capacitance retention of 50 PEDOT/GnPU sponge was $95.7 \%$ at 10,000 cycles, exhibiting excellent electrochemical stability. As for 110 PEDOT/GnPU sponge, the specific capacitance was also lightly increased in the first 50 cycles and then decreased. However, the specific 
capacitance began to increase after about 2000 cycles and kept increasing till the end of the test. The different capacitance retention behaviors of the two samples after 2000 cycles were probably due to the different amounts of PEDOT on the composites. As mentioned above, more PEDOT was polymerized on 110 PEDOT/GnPU than the 50 PEDOT/GnPU sponge, and a large portion of PEDOT fell behind the applied current without being utilized at high current density. The surface PEDOT went through the same self-activation and degradation as 50 PEDOT/GnPU, causing the increase in capacitance in the first 50 cycles and then a decrease within the first 2000 cycles. While 110 PEDOT/GnPU was kept at high current density for a period of time, the inner PEDOT started to be activated [56]. With the protection of the surface PEDOT, the activation of the underneath PEDOT took more chargedischarge cycles than the surface PEDOT, and the degradation of the PEDOT underneath was reduced compared to the surface PEDOT. Therefore, the 110 PEDOT/GnPU sponge exhibited better cycling stability than 50 PEDOT/GnPU, and the capacitance was slightly higher than the initial value at the end of 10,000 cycles. With the capacitance values and the discharge times obtained from $C D$ tests, the energy density and the power density were calculated. 110 PEDOT/GnPU exhibited the highest energy density among samples presented in this work, as $27.7 \mu \mathrm{Wh} \mathrm{cm}^{-2}$, and the power density as $0.051 \mathrm{~mW} \mathrm{~cm}^{-2}$. The energy density value is very competitive among some existing works on flexible supercapacitor electrode materials, as shown in Figure $8 \mathrm{~d}$. The areal specific capacitance and the retention of 110 PEDOT/GnPU are higher than the other reported materials listed in Table 2.

Table 2. Comparison of areal specific capacitance values of some other existing works.

\begin{tabular}{|c|c|c|c|c|c|c|}
\hline Electrode Material & Electrolyte & $\begin{array}{l}\text { Current } \\
\text { Density }\end{array}$ & $\begin{array}{l}\text { Voltage } \\
\text { Window }\end{array}$ & $\begin{array}{l}\text { Highest Specific } \\
\text { Capacitance }\end{array}$ & Capacitance Retention & Ref. \\
\hline 110 PEDOT/GnPU & $\mathrm{H}_{2} \mathrm{SO}_{4}(\mathrm{aq})$ & $0.1 \mathrm{~mA} \mathrm{~cm}^{-2}$ & $0.5 \mathrm{~V}$ & $798.2 \mathrm{mF} \mathrm{cm}^{-2}$ & $101.0 \%$ after 10,000 cycles & this work \\
\hline $\begin{array}{c}\text { MWCNT/RGO + } \\
\text { EG-PEDOT:PSS }\end{array}$ & $\begin{array}{l}\text { PC-PMMA- } \\
\text { [BMIM][TFSI] }\end{array}$ & $0.025 \mathrm{~mA} \mathrm{~cm}^{-2}$ & $1.0 \mathrm{~V}$ & $30.4 \mathrm{mF} \mathrm{cm}^{-2}$ & $99.7 \%$ after 10,000 cycles & {$[34]$} \\
\hline LRGO@PANI-MSC & $\mathrm{H}_{2} \mathrm{SO}_{4} / \mathrm{PVA}$ & $0.035 \mathrm{~mA} \mathrm{~cm}^{-2}$ & $2.0 \mathrm{~V}$ & $72 \mathrm{mF} \mathrm{cm}^{-2}$ & $93.5 \%$ after 1000 cycles & [35] \\
\hline Ni/Cu/Ag@polyamide & $\mathrm{KCl} / \mathrm{PVA}$ & $0.75 \mathrm{~mA} \mathrm{~cm}^{-2}$ & $0.8 \mathrm{~V}$ & $41 \mathrm{mF} \mathrm{cm}^{-2}$ & $\sim 30 \%$ after 5000 cycles & [39] \\
\hline $\mathrm{MnO}_{2} @$ graphite tape & $\mathrm{LiCl} / \mathrm{PVA}$ & $0.5 \mathrm{~mA} \mathrm{~cm}^{-2}$ & $0.8 \mathrm{~V}$ & $577.5 \mathrm{mF} \mathrm{cm}^{-2}$ & $\sim 78 \%$ after 5000 cycles & [40] \\
\hline $\mathrm{RGO} / \mathrm{MoS}_{2} / \mathrm{PEDOT}$ & $\mathrm{H}_{2} \mathrm{SO}_{4}(\mathrm{aq})$ & $0.5 \mathrm{~mA} \mathrm{~cm}^{-2}$ & $1.0 \mathrm{~V}$ & $241.81 \mathrm{mF} \mathrm{cm}^{-2}$ & $93.7 \%$ after 5000 cycles & [41] \\
\hline $\mathrm{MnO}_{2} @$ PEDOT & $\mathrm{Na}_{2} \mathrm{SO}_{4} / \mathrm{CMC}$ & $0.1 \mathrm{~mA} \mathrm{~cm}^{-2}$ & $1.0 \mathrm{~V}$ & $116.9 \mathrm{mF} \mathrm{cm}^{-2}$ & $87.2 \%$ after 10,000 cycles & [42] \\
\hline PPy-f-MWCNT-ESM & $\mathrm{H}_{3} \mathrm{PO}_{4} / \mathrm{PVA}$ & $0.5 \mathrm{~mA} \mathrm{~cm}^{-2}$ & $0.5 \mathrm{~V}$ & $370 \mathrm{mF} \mathrm{cm}^{-2}$ & $60 \%$ after 4000 cycles & [43] \\
\hline
\end{tabular}

\section{Conclusions}

GtPU and GnPU sponges were fabricated with the "dip and dry" technique by depositing graphite nanoplatelets and graphene nanoplatelets onto PU sponge, and then they were used as the substrates for vapor phase polymerization of PEDOT. The produced PEDOT/GtPU and PEDOT/GnPU composite sponges were employed as electrodes for supercapacitors. The resulting composite sponges exhibited greatly enhanced electric conductivity and capacitive performance compared to GtPU and GnPU substrates. The effect of graphite nanoplatelets and graphene nanoplatelets on PEDOT growth and capacitive behaviors of the resulting composite sponges were studied. At both polymerization temperatures, GnPU sponges were demonstrated to be more favorable for growth of VPP PEDOT and high specific capacitance. The variation of VPP temperature for the polymerization of PEDOT was also important for the PEDOT structure and the capacitive performance of the final electrodes. The 50 PEDOT/GnPU exhibited an areal specific capacitance of $106.6 \mathrm{mF} \mathrm{cm}^{-2}$, and $95.7 \%$ capacitance retention after 10,000 charge-discharge cycles with $20 \mathrm{~mA} \mathrm{~cm}^{-2}$. The highest areal specific capacitance of $798.2 \mathrm{mF} \mathrm{cm}^{-2}$ was obtained with $110 \mathrm{PEDOT} / \mathrm{GnPU}$ at current density of $0.1 \mathrm{~mA} \mathrm{~cm}^{-2}$. The capacitance retention of 110 PEDOT/GnPU was $101.0 \%$ after 10,000 charge-discharge cycles with $20 \mathrm{~mA} \mathrm{~cm}{ }^{-2}$. The high flexibility, high specific capacitance, excellent long-term cycling stability and low cost of these composite sponges make them competitive electrode materials for energy storage. 
Author Contributions: Methodology and investigation, L.T., L.A.S. and M.T.F.; validation, S.M.B. and B.L.; formal analysis, W.W.; data curation, L.T.; writing—original draft preparation, L.T.; writingreview and editing, L.T. and S.M.B.; supervision and funding acquisition, W.E.B. and W.E.J.J. All authors have read and agreed to the published version of the manuscript.

Funding: The work was supported by the National Science Foundation (NSF) (Grant No. IIP1318202)

Acknowledgments: We thank M. Stanley Whittingham for the access to the VMP multichannel potentiostat.

Conflicts of Interest: The authors declare no conflict of interest.

\section{References}

1. Simon, P.; Gogotsi, Y. Materials for electrochemical capacitors. Nat. Mater. 2008, 7, 845-854. [CrossRef] [PubMed]

2. Zuliani, J.E.; Tong, S.; Jia, C.Q.; Kirk, D.W. Contribution of surface oxygen groups to the measured capacitance of porous carbon supercapacitors. J. Power Sources 2018, 395, 271-279. [CrossRef]

3. Chang, L.; Stacchiola, D.J.; Hu, Y.H. An ideal electrode material, 3D surface-microporous graphene for supercapacitors with ultrahigh areal capacitance. ACS Appl. Mater. Interfaces 2017, 9, 24655-24661. [CrossRef] [PubMed]

4. Okhay, O.; Tkach, A. Graphene/Reduced Graphene Oxide-Carbon Nanotubes Composite Electrodes: From Capacitive to Battery-Type Behaviour. Nanomaterials 2021, 11, 1240. [CrossRef] [PubMed]

5. Costentin, C.; Porter, T.R.; Savéant, J.M. How do pseudocapacitors store energy? Theoretical analysis and experimental illustration. ACS Appl. Mater. Interfaces 2017, 9, 8649-8658. [CrossRef]

6. Yang, P.; Mai, W. Flexible solid-state electrochemical supercapacitors. Nano Energy 2014, 8, 274-290. [CrossRef]

7. Wang, G.; Zhang, L.; Zhang, J. A review of electrode materials for electrochemical supercapacitors. Chem. Soc. Rev. 2012, 41, 797-828. [CrossRef]

8. Iro, Z.S.; Subramani, C.; Dash, S.S. A brief review on electrode materials for supercapacitor. Int. J. Electrochem. Sci. 2016, 11, 10628-10643. [CrossRef]

9. Borenstein, A.; Hanna, O.; Attias, R.; Luski, S.; Brousse, T.; Aurbach, D. Carbon-based composite materials for supercapacitor electrodes: A review. J. Mater. Cem. A 2017, 5, 12653-12672. [CrossRef]

10. Gao, Y. Graphene and polymer composites for supercapacitor applications: A review. Nanoscale Res. Lett. 2017, 12, 387. [CrossRef]

11. Eftekhari, A.; Li, L.; Yang, Y. Polyaniline supercapacitors. J. Power Sources 2017, 347, 86-107. [CrossRef]

12. Ma, H.; Kong, D.; Xu, Y.; Xie, X.; Tao, Y.; Xiao, Z.; Lv, W.; Jang, H.D.; Huang, J.; Yang, Q.H. Disassembly-reassembly approach to $\mathrm{RuO}_{2}$ /graphene composites for ultrahigh volumetric capacitance supercapacitor. Small 2017, 13, 1701026. [CrossRef]

13. Zhao, P.; Yao, M.; Ren, H.; Wang, N.; Komarneni, S. Nanocomposites of hierarchical ultrathin $\mathrm{MnO}_{2}$ nanosheets/hollow carbon nanofibers for high-performance asymmetric supercapacitors. Appl. Surf. Sci. 2019, 463, 931-938. [CrossRef]

14. Singh, A.; Ojha, S.K.; Ojha, A.K. Facile synthesis of porous nanostructures of $\mathrm{NiCo}_{2} \mathrm{O}_{4}$ grown on rGO sheet for high performance supercapacitors. Synth. Met. 2020, 259, 116215. [CrossRef]

15. Korkmaz, S.; Tezel, F.M.; Kariper, I.A. Synthesis and Characterization of GO/ $\mathrm{V}_{2} \mathrm{O}_{5}$ Thin Film Supercapacitor. Synth. Met. 2018, 242, 37-48. [CrossRef]

16. Tong, L.; Skorenko, K.H.; Faucett, A.C.; Boyer, S.M.; Liu, J.; Mativetsky, J.M.; Bernier, W.E.; Jones, W.E. Vapor-phase polymerization of poly (3, 4-ethylenedioxythiophene)(PEDOT) on commercial carbon coated aluminum foil as enhanced electrodes for supercapacitors. J. Power Sources 2015, 297, 195-201. [CrossRef]

17. Yang, L.; Shi, M.; Jiang, J.; Liu, Y.; Yan, C.; Liu, H.; Guo, Z. Heterogeneous interface induced formation of balsam pear-like PPy for high performance supercapacitors. Mater. Lett. 2019, 244, 27-30. [CrossRef]

18. Li, B.; Lopez-Beltran, H.; Siu, C.; Skorenko, K.H.; Zhou, H.; Bernier, W.E.; Whittingham, M.S.; Jones, W.E. Vaper Phase Polymerized PEDOT/Cellulose Paper Composite for Flexible Solid-State Supercapacitor. ACS Appl. Energy Mater. 2020, 3 , 1559-1568. [CrossRef]

19. Yuan, D.; Li, B.; Cheng, J.; Guan, Q.; Wang, Z.; Ni, W.; Li, C.; Liu, H.; Wang, B. Twisted yarns for fiber-shaped supercapacitors based on wetspun PEDOT: PSS fibers from aqueous coagulation. J. Mater. Chem. A 2016, 4, 11616-11624. [CrossRef]

20. Ramirez, F.C.R.; Ramakrishnan, P.; Flores-Payag, Z.P.; Shanmugam, S.; Binag, C.A. Polyaniline and carbon nanotube coated pineapple-polyester blended fabric composites as electrodes for supercapacitors. Synth. Met. 2017, 230, 65-72. [CrossRef]

21. Liu, R.; Cho, S.I.; Lee, S.B. Poly (3, 4-ethylenedioxythiophene) nanotubes as electrode materials for a high-powered supercapacitor. Nanotechnology 2008, 19, 215710. [CrossRef] [PubMed]

22. Moussa, M.; El-Kady, M.F.; Wang, H.; Michimore, A.; Zhou, Q.; Xu, J.; Majeswki, P.; Ma, J. High-performance supercapacitors using graphene/polyaniline composites deposited on kitchen sponge. Nanotechnology 2015, 26, 075702. [CrossRef] [PubMed]

23. Sen, P.; De, A. Electrochemical performances of poly (3, 4-ethylenedioxythiophene)- $\mathrm{NiFe}_{2} \mathrm{O}_{4}$ nanocomposite as electrode for supercapacitor. Electrochim. Acta 2010, 55, 4677-4684. [CrossRef]

24. Han, J.; Dou, Y.; Zhao, J.; Wei, M.; Evans, D.G.; Duan, X. Flexible CoAl LDH@ PEDOT Core/Shell Nanoplatelet Array for High-Performance Energy Storage. Small 2013, 9, 98-106. [CrossRef] 
25. Singu, B.S.; Yoon, K.R. Highly exfoliated GO-PPy-Ag ternary nanocomposite for electrochemical supercapacitor. Electrochim. Acta 2018, 268, 304-315. [CrossRef]

26. Zhao, D.; Zhang, Q.; Chen, W.; Yi, X.; Liu, S.; Wang, Q.; Liu, Y.; Li, J.; Li, X.; Yu, H. Highly flexible and conductive cellulosemediated PEDOT: PSS/MWCNT composite films for supercapacitor electrodes. ACS Appl. Mater. Interfaces 2017, 9, 13213-13222. [CrossRef]

27. Huang, G.; Zhang, Y.; Wang, L.; Sheng, P.; Peng, H. Fiber-based $\mathrm{MnO}_{2}$ / carbon nanotube/polyimide asymmetric supercapacitor. Carbon 2017, 125, 595-604. [CrossRef]

28. Chen, W.; Rakhi, R.B.; Alshareef, H.N. High energy density supercapacitors using macroporous kitchen sponges. J. Mater. Chem. 2012, 22, 14394-14402. [CrossRef]

29. Nardecchia, S.; Carriazo, D.; Ferrer, M.L.; Gutiérrez, M.C.; del Monte, F. Three dimensional macroporous architectures and aerogels built of carbon nanotubes and/or graphene: Synthesis and applications. Chem. Soc. Rev. 2013, 42, 794-830. [CrossRef]

30. Chaudhari, N.K.; Jin, H.; Kim, B.; Lee, K. Nanostructured materials on 3D nickel foam as electrocatalysts for water splitting. Nanoscale 2017, 9, 12231-12247. [CrossRef]

31. Ren, J.; Ren, R.P.; Lv, Y.K. Stretchable all-solid-state supercapacitors based on highly conductive polypyrrole-coated graphene foam. Chem. Eng. J. 2018, 349, 111-118. [CrossRef]

32. Liang, X.; Nie, K.; Ding, X.; Dang, L.; Sun, J.; Shi, F.; Xu, H.; Jiang, R.; He, X.; Liu, Z.; et al. Highly compressible carbon sponge supercapacitor electrode with enhanced performance by growing nickel-cobalt sulfide nanosheets. ACS Appl. Mater. Interfaces 2018, 10, 10087-10095. [CrossRef]

33. Moon, I.K.; Yoon, S.; Oh, J. Three-Dimensional Hierarchically Mesoporous $\mathrm{ZnCo}_{2} \mathrm{O}_{4}$ Nanowires Grown on Graphene/Sponge Foam for High-Performance, Flexible, All-Solid-State Supercapacitors. Chem. A Eur. J. 2017, 23, 597-604. [CrossRef]

34. Lee, H.; Jung, G.; Keum, K.; Kim, J.W.; Jeong, H.; Lee, Y.H.; Kim, D.S.; Ha, J.S. A Textile-Based Temperature-Tolerant Stretchable Supercapacitor for Wearable Electronics. Adv. Funct. Mater. 2021, 2021, 2106491. [CrossRef]

35. Gholami Laelabadi, K.; Moradian, R.; Manouchehri, I. One-Step Fabrication of Flexible, Cost/Time Effective, and High Energy Storage Reduced Graphene Oxide@ PANI Supercapacitor. ACS Appl. Energy Mater. 2020, 3, 5301-5312. [CrossRef]

36. Guo, Q.; Li, J.; Zhang, B.; Nie, G.; Wang, D. High-performance asymmetric electrochromic-supercapacitor device based on poly (indole-6-carboxylicacid) $/ \mathrm{TiO}_{2}$ nanocomposites. ACS Appl. Mater. Interfaces 2019, 11, 6491-6501. [CrossRef]

37. Shahidi, S.; Kalaoglu, F. In situ deposition of nickel nano particles on polyester fabric and its application as a flexible electrode in supercapacitor. J. Ind. Text. 2020, 2020, 1528083720944252.

38. Li, S.; Tao, Y.; Maryum, P.; Wang, Q.; Zhu, J.; Min, F.; Cheng, H.; Zhao, S.; Wang, C. Bifunctional polyaniline electroconductive hydrogels with applications in supercapacitor and wearable strain sensors. J. Biomater. Sci. Polym. Ed. 2020, 31, 938-953. [CrossRef]

39. Pullanchiyodan, A.; Manjakkal, L.; Dahiya, R. Metal Coated Fabric Based Asymmetric Supercapacitor for Wearable Applications. IEEE Sens. J. 2021, 2021, 1. [CrossRef]

40. Yu, N.; Xiong, R.; Wang, Y.; Zhou, C.; Li, Y.; Pang, C.; Li, Z.; Zou, L.; Guo, K. Facile fabrication of low-cost and scalable graphite tape as novel current collectors for flexible supercapacitors. J. Alloys Compd. 2021, 861, 158476. [CrossRef]

41. Chen, Y.; Bai, J.; Yang, D.; Sun, P.; Li, X. Excellent performance of flexible supercapacitor based on the ternary composites of reduced graphene oxide/molybdenum disulfide/poly (3, 4-ethylenedioxythiophene). Electrochim. Acta 2020, 330, 135205. [CrossRef]

42. He, Q.; Ye, J.; Peng, Z.; Guo, Y.; Tan, L.; Chen, Y. Electrodeposition of poly (3, 4-ethylenedioxythiophene) coated manganese dioxide nanospheres for flexible asymmetric planar supercapacitor with superior energy density. J. Power Sources 2021, 506, 230176. [CrossRef]

43. Alcaraz-Espinoza, J.J.; de Melo, C.P.; de Oliveira, H.P. Fabrication of highly flexible hierarchical polypyrrole/carbon nanotube on eggshell membranes for supercapacitors. ACS Omega 2017, 2, 2866-2877. [CrossRef] [PubMed]

44. Arena, A.; Branca, C.; Ciofi, C.; D’Angelo, G.; Romano, V.; Scandurra, G. Polypyrrole and Graphene Nanoplatelets Inks as Electrodes for Flexible Solid-State Supercapacitor. Nanomaterials 2021, 11, 2589. [CrossRef]

45. Cho, B.; Park, K.S.; Baek, J.; Oh, H.S.; Koo Lee, Y.E.; Sung, M.M. Single-crystal poly (3, 4-ethylenedioxythiophene) nanowires with ultrahigh conductivity. Nano Lett. 2014, 14, 3321-3327. [CrossRef]

46. Li, B.; Skorenko, K.H.; Qiu, H.; Mativetsky, J.M.; Dwyer, D.B.; Bernier, W.E.; Jones, W.E. Effects of interfacial modification for vapor phase polymerized PEDOT on glass substrate. Synth. Met. 2020, 260, 116293. [CrossRef]

47. Chen, X.; Jiang, F.; Jiang, Q.; Jia, Y.; Liu, C.; Liu, G.; Xu, J.; Duan, X.; Zhu, C.; Nie, G.; et al. Conductive and flexible PEDOTdecorated paper as high performance electrode fabricated by vapor phase polymerization for supercapacitor. Colloids Surf. A Physicochem. Eng. Asp. 2020, 603, 125173. [CrossRef]

48. Tong, L.; Liu, J.; Boyer, S.M.; Sonnenberg, L.A.; Fox, M.T.; Ji, D.; Feng, J.; Bernier, W.E.; Jones, W.E. Vapor-phase polymerized poly (3,4-ethylenedioxythiophene)(PEDOT)/ $\mathrm{TiO}_{2}$ composite fibers as electrode materials for supercapacitors. Electrochim. Acta 2017, 224, 133-141. [CrossRef]

49. Winther-Jensen, B.; Chen, J.; West, K.; Wallace, G. Vapor phase polymerization of pyrrole and thiophene using iron (III) sulfonates as oxidizing agents. Macromolecules 2004, 37, 5930-5935. [CrossRef] 
50. Weakley, A.T.; Warwick, P.C.T.; Bitterwolf, T.E.; Aston, D.E. Multivariate Analysis of Micro-Raman Spectra of Thermoplastic Polyurethane Blends Using Principal Component Analysis and Principal Component Regression. Appl. Spectrosc. 2012, 66, 1269-1278. [CrossRef]

51. Ferrari, A.C. Raman spectroscopy of graphene and graphite: Disorder, electron-phonon coupling, doping and nonadiabatic effects. Solid State Commun. 2007, 143, 47-57. [CrossRef]

52. Obeidat, A.M.; Rastogi, A.C. Electrochemical energy storage performance of asymmetric PEDOT and graphene electrode-based supercapacitors using ionic liquid gel electrolyte. J. Appl. Electrochem. 2018, 48, 747-764. [CrossRef]

53. Bellunato, A.; Tash, H.A.; Cesa, Y.; Schneider, G.F. Chemistry at the Edge of Graphene. Chem. Phys. Chem. 2016, 17, 785-801. [CrossRef]

54. Tahir, M.; He, L.; Haider, W.A.; Yang, W.; Hong, X.; Guo, Y.; Pan, X.; Tang, H.; Li, Y.; Mai, L. Co-electrodeposited porous PEDOT-CNT microelectrodes for integrated micro-supercapacitors with high energy density, high rate capability, and long cycling life. Nanoscale 2019, 11, 7761-7770. [CrossRef]

55. Mohd Abdah, M.A.A.; Zubair, N.A.; Azman, N.H.N.; Sulaiman, Y. Fabrication of PEDOT coated PVA-GO nanofiber for supercapacitor. Mater. Chem. Phys. 2017, 192, 161-169. [CrossRef]

56. Li, L.; Zhang, N.; Zhang, M.; Zhang, X.; Zhang, Z. Flexible $\mathrm{Ti}_{3} \mathrm{C}_{2} \mathrm{~T}_{\mathrm{x}} /$ PEDOT: PSS films with outstanding volumetric capacitance for asymmetric supercapacitors. Dalton Trans. 2019, 48, 1747-1756. [CrossRef] 